Article

\title{
Sustainable Virtual Teams: Promoting Well-Being through Affect Management Training and Openness to Experience Configurations
}

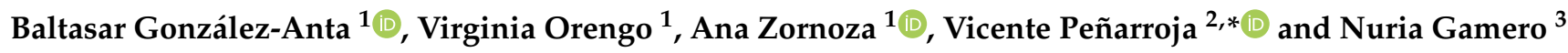 \\ 1 Research Institute IDOCAL, University of Valencia, 46010 Valencia, Spain; juan.b.gonzalez@uv.es (B.G.-A.); \\ virginia.orengo@uv.es (V.O.); Ana.Zornoza@uv.es (A.Z.) \\ 2 Faculty of Economics and Business, Universitat Oberta de Catalunya (UOC), 08035 Barcelona, Spain \\ 3 Department of Social Psychology, Faculty of Psychology, University of Seville, 41018 Sevilla, Spain; \\ ngamero@us.es \\ * Correspondence: vpenarrojac@uoc.edu
}

Citation: González-Anta, B.; Orengo, V.; Zornoza, A.; Peñarroja, V.; Gamero, N. Sustainable Virtual Teams: Promoting Well-Being through Affect Management Training and Openness to Experience Configurations.

Sustainability 2021, 13, 3491. https:// doi.org/10.3390/su13063491

Received: 28 February 2021

Accepted: 19 March 2021

Published: 22 March 2021

Publisher's Note: MDPI stays neutra with regard to jurisdictional claims in published maps and institutional affiliations.

Copyright: (c) 2021 by the authors. Licensee MDPI, Basel, Switzerland. This article is an open access article distributed under the terms and conditions of the Creative Commons Attribution (CC BY) license (https:// creativecommons.org/licenses/by/ $4.0 /)$
Abstract: A disruptive digitalization recently occurred that led to the fast adoption of virtual teams. However, membership diversity and team virtuality threaten members' well-being, especially if faultlines appear (i.e., subgroups). Considering the job demands-resources model and the role of group affect in shaping members' perceptions of well-being, we test the effectiveness of a short-term affect management training for increasing members' eudaimonic well-being. Moreover, based on the trait activation theory and the contingent configuration approach, we draw on the personality composition literature to test how different openness to experience configurations of team level and diversity together moderate the effect of the training. Hypotheses were tested using a pre-post design in an online randomized controlled trial in an educational context in Spain, with a sample of 52 virtual teams with faultlines. Results show that affect management training increased eudaimonic well-being. Furthermore, there was a moderation effect (three-way interaction) of openness to experience configurations, so that the training was more effective in teams with high levels and low diversity in openness to experience. We discuss implications for training, well-being, and personality composition literature. This study helps organizations develop sustainable virtual teams with engaged members through affect management training and selection processes based on the openness to experience trait.

Keywords: sustainable virtual teams; eudaimonic well-being; affect management training; faultlines; personality composition; team configurations; openness to experience

\section{Introduction}

Sustainable and competitive organizations need to pay attention not only to financial results but also to the social dimensions within the organization [1-3]. Among these dimensions, well-being is an essential result in organizational teams because it has been related to team effectiveness [4]. Many of these teams have now become virtual and moved to telecommuting or virtual teamwork, making it possible for employees to work without temporal or geographical boundaries [5,6]. The virtualization of organizational teams took place, initially, because of the broad generalization of information and communication technologies $[5,7,8]$ and, more recently, due to the disruptive digitalization caused by the COVID-19 pandemic [8,9]. In this regard, virtual teams are defined as groups of geographically dispersed members who interact through computer-mediated communication to pursue common goals $[10,11]$ regardless of physical distance, time zones, or other barriers [6]. To be sustainable, virtual teams need to experience well-being, which leads to team effectiveness. However, scholars continually try to identify new ways to improve the sustainability of team members operating in virtual environments [12]. Their dispersion leads to high diversity $[11,12]$ in terms of personality, demographics, or educational 
background, among others. Diversity may have positive effects on team results [12-15]. Nevertheless, due to the reduced richness of the information exchange and interpersonal contact [10], diversity can also have also negative consequences [16]. Individuals may look for other members within the virtual team with whom they share characteristics, thus leading to team fragmentation. In these circumstances, diversity may be a hindrance due to the emergence of faultlines [17,18], that is, hypothetical lines splitting a team into relatively homogeneous subgroups because of the alignment of two or more individual characteristics $[19,20]$. Ample prior research has shown the negative effects of faultines on team results (e.g., $[17,18,20-23])$. The appearance of subgroups accentuates inter-member negative differentiation between members perceived as the in-group and those perceived as the out-group [24]. Combined with the fast-paced generalization of virtual teams in educational [25] and organizational environments [26,27], this adverse context could seriously harm team members' well-being [25-28].

In this setting, the job demands-resources model [29] provides a useful framework for studying virtual teams' sustainability [16]. Moreover, this model has been used to study well-being in educational environments [30] and the implementation of innovative teaching methods (e.g., instructional technological tools) [31,32]. Virtualization of work processes could increase technology-induced demands [33], at least in the short term, as well as emotional demands [16], leading to negative outcomes [34]. In fact, technology has mainly been studied in terms of its role as a barrier, rather than an asset, in telework and virtual teamwork literature [5]. In parallel, if members lack the proper skills and knowledge resources, the motivational process is hampered [34,35]. This demands-resources imbalance reduces team members' energy and motivation and increases their cognitive effort, producing exhaustion and disengagement $[16,34]$. In brief, working in virtual teams with faultlines could reduce their eudaimonic well-being. Following previous research [3,4], we focus on team work engagement as a proxy for eudaimonic well-being. Team work engagement (TWE) is defined as a "shared, positive, fulfilling, motivational emergent state of work-related well-being" [36] (p. 5) characterized by team vigor, dedication, and absorption [37]. TWE is fundamental in virtual teams because it motivates team members to achieve common goals, despite the adverse conditions of the environment. Teams with TWE invest time in thoroughly establishing their goals and steps, creating a coordinated plan that drives them through the sequence to achieve the shared objective [38].

Along these lines, some studies have acknowledged the importance of engagement in virtual teams' outcomes, such as the transfer of tacit knowledge, opportunities for employee development, and performance results in workers and students, among others $[12,16,36,39,40]$. Despite this, the literature is still scarce, and surprisingly few efforts have been made to identify ways to promote TWE in the virtual context. In fact, Gilson and colleagues [41] called for more research on engagement in virtual teams and subgroups because working virtually implies unique challenges for team members. In this regard, we propose affect management as a driver of TWE in teams [38]. Affect management involves the use of emotion regulation techniques and strategies (resources) that create shared positive affective experiences within a group [42,43]. In turn, these positive experiences facilitate the involvement and engagement of team members $[16,44,45]$.

However, affect is difficult to show and manage in computer-mediated communication settings [46,47], and there could be a lack of appropriate skills within this context [34]. Different strategies can be used to improve the interactions and well-being of students and workers in virtual environments, for example, management of leadership [6,8,15], ideals [2], or experiential classes and training [12,34,48]). In the context of virtual settings, training is a particularly useful way to provide skills that improve the resources-demands imbalance [34]. Training can help to develop engagement in the short time span of a virtual team's lifecycle [49]. Therefore, the first goal of this study is to test the efficacy of affect management training in increasing TWE in virtual teams with subgroups.

Beyond studying the direct effects of affect management training, we also address the role of personality composition. Teams' personality composition could affect team pro- 
cesses, norms, and climate [50]. We particularly focus on openness to experience as one of the big five factors that could help to manage interaction processes related to the resourcesdemand imbalance in virtual settings [51]. Moreover, the way openness to experience is configured is of special relevance in teams with subgroups [52]. Openness to experience configuration(s) (OEC) is a deep-level composition variable [53] that encompasses the way individual openness to experience aggregates within a given team, combining level and diversity. In this study, a contingent configuration approach [54] is used. Thus, we argue that openness to experience will manifest and influence team results in a complex structure based on the role of job demands and resources. Supporting this idea, the trait activation theory [55] argues that when working in teams, situational features and social cues act as contingent factors that influence the display of personality traits, as in the case of openness to experience.

Prior research has considered a similar framework when studying engagement and personality [56]. Despite this, there has been debate about the way personality configurations influence team outcomes $[57,58]$. In this context, personality configurations have been studied through different operationalizations. For example, mean values of individual scores (i.e., team magnitude or level [59]) have been linked to team performance and results $([52,60]$. However, other studies have also examined personality in terms of SD values (i.e., diversity), linking it to team outcomes such as performance or interaction styles [61]. Thus, the myriad of results $[58,62,63]$ may be due to the different measurement approaches to personality composition and the complexity of considering various types of configurations existing in a team [58], so that specific compositional effects may not be properly understood $[64,65]$. The inconsistent results found to date are worrisome because they imply a lack of proper understanding of composition effects in virtual teams, which may lead to inadequate selection procedures and problems for virtual team' sustainability, especially if these teams have faultlines. Thus, there is a need for research that creates knowledge consensus [66] about how different personality configurations influence team results, particularly in virtual teams, where it is still an emerging topic [67]. Consequently, based on the contingent configuration approach [54], we propose that for a team to successfully increase its TWE through affect management, it must have high levels of openness to experience but also low diversity in this trait. In other words, OEC will moderate the effects of the training on TWE by combining team-level openness and diversity in a complex configuration. In doing so, to the best of our knowledge, this study is the first to combine OEC to evaluate their interactive effects on affect management training.

In the present study, we conduct an online study with control and experimental conditions using a pre-post design with virtual teams in a higher education context. Students and workers need to develop skills for working in virtual and cross-cultural teams $[12,26,34]$. Thus, our aim is to test the effectiveness of affect management training in increasing team members' TWE. Moreover, we study the moderating role of OEC, in terms of team level and diversity, in virtual teams with faultlines.

\subsection{Affect Management Training and Eudaimonic Well-Being}

Well-being is a complex construct with two broad perspectives that shape it [68]: the hedonic and eudaimonic well-being perspectives [69]. The hedonic approach defines well-being as avoiding pain and pursuing pleasure, whereas the eudaimonic approach focuses on a search for meaning and self-realization beyond the pain-pleasure equation. Thus, it represents the extent to which a person is fully functioning [70]. As prior research noted, at the group level, eudaimonic well-being is still an avenue for future research $[4,45]$, particularly regarding engagement [16,41].

To understand how TWE develops in virtual teams of students, we build on the job demands-resources theory [29]. This theory posits that there are two parallel processes that run independently and can affect the perception of TWE: the health impairment process, which arises from job demands, and the motivational process, which stems from job resources [71]. On the one hand, job demands involve costs (e.g., cognitive or emotional 
demands) because they require sustained effort from the worker. On the other hand, job resources are those characteristics that help reduce demands and achieve team goals [29]. We contend that there is an increase in demands in virtual teams with subgroups. The diminished media richness $[10,16]$, the short-term duration of these teams $[10,49]$ that may have been created without the proper skills [34], and the missing non-verbal communication cues may increase the cognitive effort required in virtual teams [72]. In addition, we argue that subgroups also increase the emotional demands. Geographical dispersion and reduced communication due to computer-mediated communication may contribute to an "out of sight, out of mind" attitude toward other members [17], making cultural, educational, or personal diversity more salient. Thus, mutual characteristics and differences from other members are highlighted. If two or more characteristics align, social categorization processes lead to faultlines. Social categorization triggers favoritism within the subgroup and negative attributions toward the other subgroup, producing negative interactions and outcomes (e.g., lowered cooperation) [14]. Consequently, negative effects may arise [22,23], and members can feel emotionally charged [47] and experience high levels of social distance and isolation [73], which negatively affects their TWE [16] because these teams are more susceptible to losing group motivation $[16,74]$. To address this situation, we propose an affect management training that increases participants' personal resources in order to reduce the resources-demands mismatch and increase their TWE. We propose that there is a demands-resources imbalance in this setting because virtual teamwork, unlike working in face-to-face teams, requires the development of specialized competencies through specific training [34]. In this vein, group affect is a structural part of team dynamics [45]. Group affect is created and maintained as a shared experience among team members $[43,45]$ that forms a collective perception from the individual experiences [75]. Recently, emphasis has been placed on the role of collective affect in shaping the way teams interact and the outcomes they produce (e.g., their well-being) [43,45,74]. In addition, negative affective experiences reduce team results because they distract team members from the task itself and their efforts to complete it [45].

In this regard, virtual teamwork is characterized by a low-information environment with limited communication frequency and quality and a greater focus on the task than on the relationships [21,47]. Therefore, our training will provide virtual team members with resources and strategies that allow them to manage the group affect [42]. It will also help to produce de-categorization within the team to reduce the negative effects of subgroups.

Affect management training involves techniques such as calming members down, controlling frustration levels, improving team morale, and correctly using online communication resources (e.g., managing the influence of non-verbal online cues with other members, [47]). Moreover, strategies to leverage affective team climate are also taught, such as joking to soften negative affect, revaluating negative situations, or acknowledging members' contributions [42]. These affective expression and regulation techniques are usually spontaneously displayed in face-to-face communication [76]. In contrast, computer-mediated communication requires purposeful actions to share affective experiences [47]. We stream the training program through an online text-based environment because, despite the technological developments, text-based communication is still the prevalent computer-mediated communication $[33,47,77]$. Although initial theories considered text-based communication to be a poor medium for the transmission and regulation of affect $[46,78]$, we propose that text-based communication can be used to convey affective information that is correctly perceived and create shared positive affect, even if subgroups are present. In this regard, prior research proposed a reciprocal relationship between affect and TWE [38,44], with training being a potential tool for this purpose [38]. The correct provision and use of resources and strategies (e.g., use of capital letters or emoticons, situation re-evaluation, $[42,47,79])$ compensate for the increased demands. Then, through emotional contagion among team members $[47,80]$, affective experiences are mirrored by other team members, thus helping to increase TWE. Taking into account the previous arguments and findings, we propose the following hypothesis: 
Hypothesis 1 (H1). Affect management training will positively affect TWE in virtual teams with subgroups.

\subsection{The Moderating Role of OEC}

The role of personality is essential once team interaction unfolds [81], and team tasks require intense collaboration [82], as in the case of short-term virtual teams. Personality traits can shape interaction processes linked to well-being within the team, especially in selfmanaged teams where the lack of formal structures allows interactions to evolve and shows the role of personality in members' perceptions [83]. Additionally, personality has been labeled as a closer antecedent of affective orientations and a more powerful predictor of team results than demographic characteristics [54]. In spite of this, personality composition has hardly been studied in the context of virtual teams [67]. However, there are personality configurations and traits that help teams perform better within a virtual environment [81]. Thus, we focus on a particular trait of the big five factor model [84], openness to experience. Whereas some traits are fundamental in face-to-face teams, openness to experience is important in settings with diminished media richness, such as work in virtual teams [63], or when subgroups exist [52]. The results on openness to experience and team well-being are mixed [52], particularly considering sample and situational characteristics, and there has been a call for more research in this line [63]. In this regard, the many operationalizations (e.g., $[60,61,85-87])$ and conceptual frameworks and the influence of contextual factors $[63,88]$ contribute to criticism of personality composition research and variations in the findings $[54,58,63]$. Initial research proposed isomorphic aggregation, where group personality traits consist of a symmetric combination of individual personality traits (team level). Further models viewed group personality as a complex combination of individual attributes $[89,90]$ in which the way the trait coalesces is studied, and so heterogeneity (i.e., dispersion or diversity) of personality starts to be considered relevant [54]. Consequently, we simultaneously address openness to experience operationalizations (team level and diversity) and test how they moderate the effects of affect management training on TWE, in an effort to disentangle how different patterns of this trait can be applied to improve team results in virtual teams with faultlines.

For this purpose, we use a contingent configuration approach to study the role of OEC in virtual teams of higher education students. As Moynihan and Peterson [54] state, when studying personality in teams, it is necessary to integrate contingent and configuration views in order to embrace the complexity of personality in teams. The contingent view allows us to analyze the specific circumstances in which some personality traits will be more effective for team results, considering that each personality trait has its own characteristics and particular effects on team well-being. The latter helps us understand the internal dynamics of the team beyond classic personality level studies. Therefore, we focus on a trait that will influence team results through a complex combination of team level and diversity.

Specifically, the contingent approach emphasizes the level of certain personality traits interacting with situational characteristics [54]. We adopt this approach and build on the trait activation theory [55] and previous evidence to consider that openness to experience influences team outcomes in different ways depending on the situational demands [55,56]. Specifically in teams, social cues may act as personality activators. Thus, we propose that the affect management training activities (socially established behaviors agreed on by the team about how to transmit affect online) may act as trait-relevant situational cues that facilitate the display of personality traits [55]. Consequently, although the virtuality of the team and the presence of subgroups may negatively influence openness to experience, this trait could easily be manifested and improve the effects of the training due to the safe environment it generates. Therefore, we propose that openness to experience at the team level, built on the mean values of the individual trait, can appear and benefit TWE by making members more willing to acquire the competencies of the affect management training. 
Open individuals are characterized by intellectual curiosity, willingness to experiment, tolerance to ambiguity, a preference for novelty, imagination, and creativity $[84,91]$. Thus, their willingness to explore and appreciate new environments and experiences [84] makes this trait essential in a virtual teamwork environment. It may have a moderating role because open team members in virtual contexts will quickly learn and use computer-mediated communication resources and strategies [51], and they usually do well in training and learning environments [65]. Open team members could perceive demands as challenges that allow them to learn and expand their resources, thus promoting engagement [30]. In teams, the level of this trait has been proposed as a facilitator of cognitive resources [87] and may also enhance the effects of affective resources. Teams with high team levels of this trait will be more willing to try new ways of working [50] and engage in flexible innovative behaviors based on new information [92], thus being more favorable to applying resources and strategies to manage group affect. In addition, team-level openness to experience will improve the effects of the training in spite of subgroups because this trait is closely linked to the essence of working in a diverse environment $[52,93]$. Less open individuals prefer the status quo and are not comfortable with change [94]. Thus, if a team has low team-level openness, its members may prefer working with the subgroup with which they already identify, rather than focusing on the resources and strategies provided by affect management. Supporting this idea, Homan and colleagues [52] found, among other results, that high team-level openness to experience was positive for teams with faultlines. Therefore, the negative inter-subgroup biases that arise in teams with subgroups may depend on members' openness to experience [52]. Consequently, the higher the level of openness within the team, the more likely its members will be to "bridge" faultlines because they will consider the different attitudes, viewpoints, and ideas of other members [52,95].

In addition to the team level, personality diversity, that is, the variability in the individual scores of group members, has been studied as a group-level construct and examined as a predictor of relevant group-level outcomes $[89,96,97]$. Especially in the context of tasks with frequent interactions, diversity in team-level personality traits helps to predict team outcomes [63]. We operationalize openness to experience composition in terms of diversity through standard deviation [57]. This has been shown to be an effective way to measure diversity when examining interaction effects, especially considered together with the team level [98], and it is an adequate option for this particular trait [87]. This openness to experience diversity refers to the extent to which members are homogenous in the trait of openness to experience [56]. This operationalization helps to discover the impact of unique configurations compared to the personality level alone [59]. In sum, we depart from previous studies that emphasized the role of the team level to propose an interactive effect between the OEC team level and diversity. Hence, we are considering various aggregation approaches to personality composition that allow us to properly understand its role and impact on team results [99].

As in the case of team-level openness, results on whether high or low diversity in openness to experience will benefit team outcomes are mixed (e.g., [65,87,100]). For example, Hoch and Dulebohn [67] propose that high diversity in openness to experience may be better for virtual team effectiveness because teams with low diversity levels will experience distractions and, consequently, lower performance. If we consider the role of diversity in well-being, low diversity on student teams is related to both satisfaction and team results [100]. Meta-analytic results found that openness to experience diversity was not related to team performance in student teams, but it was negatively related to team performance in professional teams. However, a lack of clear findings about openness to experience diversity was also highlighted, as well as sample limitations [62].

We argue that although studying the role of diversity is important in analyzing the way team members engage in teamwork [90], it is necessary to study it in combination with other composition measures. Consequently, in addition to a high team level, teams with low diversity in openness to experience will benefit more from the training than teams with high diversity. Open team members will be more responsive to environmental challenges. 
Consequently, they will be more prone to participating in globally distributed ways of working, such as virtual teams [67]. Therefore, if there is a high team level of openness and low diversity, more team members will be willing to work in virtual team settings. Moreover, because we study teams with subgroups, high diversity in openness among members may deepen inter-subgroup biases created by the presence of faultlines. Thus, low diversity is better for improving TWE via training.

In this study, we propose a best pattern of OEC (high team level and low diversity) to influence team results. As Stipelman [63] stated, studies on the effects of openness diversity (vs. level) on team results have not provided evidence of a compelling effect. Team-related well-being will be present when the members perceive that they fit the team [101] in terms of personality, which helps their motivation and team affective results [54]. Therefore, we argue that the training improves TWE because members are able to manage affect in a "new" virtual environment and overcome subgroups by focusing on the whole team. This effect will be greater if members have an adequate team level of openness that is homogeneous within the team. Thus, we propose that there is an optimum configuration that will improve team outcomes, where higher levels of team-level openness will increase the effects of the training only when the team is also homogeneous in this trait (low diversity). Considering the previous theoretical rationale and empirical findings, we hypothesize the following:

Hypothesis 2 (H2). OEC will moderate the effect of affect management training on TWE, so that the effect is positive and stronger when there is high team-level openness and low diversity.

\section{Materials and Methods}

\subsection{Sample}

The sample consisted of 52 virtual teams with four members each. The 208 participants in the study were undergraduate students from Work, Organizational, and Personnel Psychology courses in public Spanish universities. Participants voluntarily joined the study and received course credit for doing so. All the teams had the same participants during the entire study. Regarding their demographic characteristics, the mean age was $20.9(\mathrm{SD}=5.31)$, and $69.2 \%$ of the sample were women $(\mathrm{N}=144)$. This study was part of a larger investigation about virtual team intervention and effectiveness. The University Ethics Committee approved the project, and confidentiality of individual responses was guaranteed. All participants were asked for informed consent for their participation and the use of the data for research purposes.

\subsection{Design and Procedure}

We carried out a randomized controlled trial with a pre-post design. This study included a between-subjects factor (training) and a within-subjects factor (time of measurement: pre-post intervention). The entire study took place through an online web-tool specifically designed for dispersed synchronous interaction among team members. This web-tool had a text chat with emoticons and a panel to broadcast video, instructions, and training, either individually or in groups. It also allowed participants to interact during the activities by answering the training exercises or doing the experimental tasks together.

Procedure. We graphically depict the design and procedure in Figure 1. As the figure shows, participants first attended an informative face-to-face meeting in which they received information about the use of the online web-tool and rules. They also completed an initial questionnaire with demographic questions and the Openness to Experience scale, among others. Then, groups were formed and randomly allocated to the training condition or the waitlist control condition. After that, the study took place for a period of approximately four weeks. On a weekly basis, teams in the training condition engaged in the pre-training experimental session, received the affect management training, and participated in the post-training experimental session. Teams in the control condition first participated in the two teamwork sessions and then received the training. 


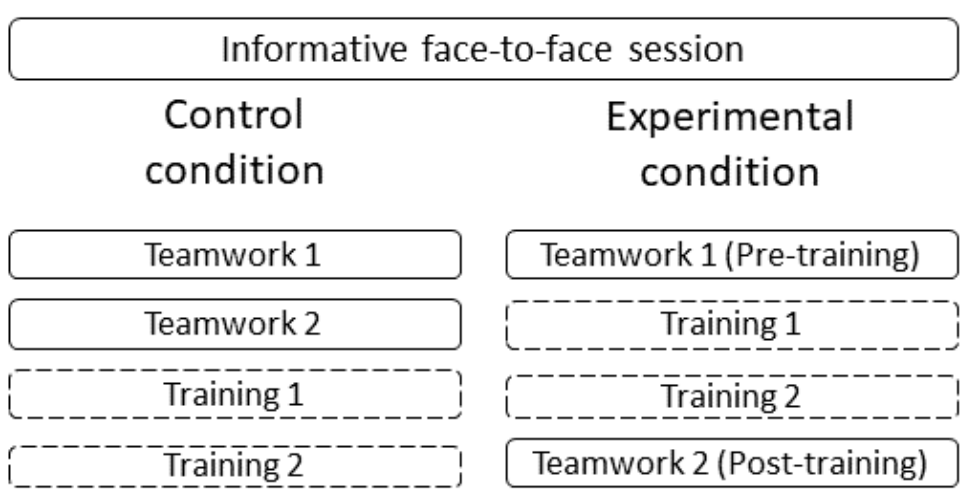

Figure 1. Scheme of the research design of this study.

Group formation. Each virtual team was composed of two dyads that formed each of the subgroups. These dyads had specific aligned diversity characteristics in order to elicit subgroup perceptions within each team. First, the university of origin was used, with each dyad within a team being from a different university in Spain. Moreover, on the initial questionnaire, we asked participants for their favorite leisure activities from a checklist. Then, as in prior research [102], we created two bogus adventure profiles (bold vs. thoughtful). Then, we randomly formed the dyads based on the same adventure profile and university, and we created virtual teams with two opposing dyads to create the faultline.

Following previous faultline studies (e.g., [22,103]), we also performed specific experimental manipulations to elicit subgroup perceptions. First, the official colors and heraldry of each university were present during the interaction in the virtual web-tool. In the pre-training session, participants were explicitly told about their profiles and the different profiles of the other two members. This was also reinforced by a zero-sum game in which they allocated resources to their two universities without being allowed to split the budget in half.

Experimental task. In the pre- and post-training sessions, each team performed an intellective decision-making task. Specifically, they engaged in two different "survival" tasks [104] integrated through digital storytelling. These tasks put participants in a hypothetical dangerous situation, and they had to put a list of pre-defined objects in order depending on their relevance for surviving the imminent risk. Virtual team experimental studies have commonly used these sorts of tasks (e.g., $[18,105])$. In the pre-training session, they first organized the objects in pairs to strengthen the perception of subgroups, and then they had to agree on a common order as a team.

Affect management training. The affect management training consisted of two sessions. The first training session focused on emotion identification, expression, and regulation in virtual teams. Participants were taught the importance of affective experiences online, the use of shared codes, and the techniques to express and understand emotions in virtual contexts (paralinguistic cues, chronemics, and emoticons $[106,107])$. The second session was designed to work on the affective climate while interacting online as a team. We taught them how to foster a positive affective climate using strategies (e.g., sending motivational messages to achieve common goals) for computer-mediated communication.

In each training session, first, an individual section was held. This individual part lasted about $25 \mathrm{~min}$ and consisted of theoretical explanations and individual practical activities. Once all the participants had completed the individual section, the group section presented similar exercises related to the contents of the session, but now all the members had to agree on the answers, generating a shared understanding of how to manage affect in the virtual environment. For example, they were presented with a strategy, and they had to write two possible group work situations where they considered it useful to apply this strategy to maintain a positive group work climate (or avoid a bad emotional climate). 


\subsection{Measures}

Openness to Experience Configurations: Openness to experience was measured with ten items on the Big Five Inventory that measure this trait. We used the validated Spanish version by Benet-Martínez and John [108]. The items were rated on a five-point Likert scale ranging from 1 (strongly disagree) to 5 (strongly agree). Examples of the items are "I see myself as someone who is curious about many different things" and "I see myself as someone who is original, comes up with new ideas". Cronbach's $\alpha$ for this variable was 0.76 . As noted above, we used the two most common operationalizations of team level and diversity, the aggregated mean values of the individual scores and the mean values of standard deviations of openness to experience within each team.

Team Work Engagement: We measured this construct with an adapted version of the Team Work Engagement Scale (TWES-9; [38]), which is composed of nine items. The items were scored on a six-point Likert scale ranging from 1 (strongly disagree) to 6 (strongly agree). The primary scale of the TWES-9 contains three dimensions: vigor, dedication, and absorption. These dimensions are part of the original individual-level construct. Despite this, previous studies $[38,109]$ propose that a one-dimensional structure fits engagement better at the group level.

Thus, this study uses TWE as an emergent shared state of work-related well-being. Examples of items are: "When we are working together, we feel bursting with energy" or "We are enthusiastic about this task". We used this variable at the pre- and post-training sessions. Cronbach's $\alpha$ values for this variable were 0.93 and 0.96 . Moreover, this variable was measured at the individual level but aggregated to create a team-level construct based on a referent-shift consensus model [96]. To ascertain that the aggregation can be carried out, ICC(1) (intraclass correlation coefficient) and $R_{W G(J)}$ were calculated in both experimental sessions [110]. ICC(1) for pre-training was 0.10 and for post-training 0.15 . Regarding $\mathrm{R}_{\mathrm{WG}(\mathrm{J})}$, the values were $0.091(\mathrm{SD}=0.16)$ for pre-training and $0.86(\mathrm{SD}=0.29)$ for post-training. All these values are above the classic cut-off points for these indexes [110], thus supporting our chosen approach to aggregate survey data at the team level.

Control variable: Team familiarity: Given our research context (teams with subgroups interacting online in a randomized experimental design), we specifically aimed to omit the influence of being acquainted with other team members so that it would not be a confounding variable in the studied relationships. Prior research has shown that familiarity may influence virtual team results [111], specifically when the team collaborates online to establish group norms [112], as in the case of our training. In this study, team familiarity was measured as previously knowing other team members [113,114]. As in prior research (e.g., [113]), in the pre-training session, we asked participants, "To what extent did you know each of your teammates before the experiment?" They rated their familiarity with each of the other three team members on a scale from 1 (not at all) to 5 (a lot). A higher mean rating on this scale would indicate high familiarity among team members. Thus, we controlled this variable in order to isolate the effects of the study variables and manipulations conducted, which could be affected by prior knowledge of the teammates, with a particular emphasis on affective experiences and subgroup perceptions.

\subsection{Data Analysis}

Preliminary analyses included randomization checks and manipulation checks for the affect management training and the identification with the subgroup by means of $t$-tests for independent samples. SPSS V.26 was used to test the hypotheses. To test Hypothesis 1, we conducted a mixed Analysis of Variance (ANOVA) because there was a between-subjects factor and a within-subjects factor. We introduced the intervention condition (training-control group) as the between-subjects variable and TWE mean values at pre- and post-intervention as the within-subjects variable.

We tested the hypothesis using hierarchical ordinary least squares (OLS) regression. Continuous moderating variables were mean-centered. Predictors were entered into the equation in six successive steps. First, we introduced the study control variable and 
controlled for the stability effect by introducing pre-intervention TWE. In the second and third steps, we introduced the affect management training (coded as a dummy variable where 0 represents the control group and 1 represents the experimental group) and the moderating variables (OEC team level and diversity), estimating the direct effects of these variables. In the fourth step, the interaction terms between the training and the moderating variables were entered. In the fifth step, we added the interaction term between the two moderating variables. Finally, in the sixth step, the three-way interaction term (affect management training, OEC team level, and diversity) was entered.

\section{Results}

\subsection{Randomization and Manipulation Checks}

Randomization was checked to ascertain that there were no initial differences in the TWE levels before the intervention. The results were non-significant $(t(50)=0.918$, $p=0.36$ ). Therefore, teams were adequately randomized across the experimental and control conditions.

Regarding the manipulation checks, for the affect management training, we followed previous studies (e.g., [22,115]) and assessed team members' perceptions of whether they correctly perceived and used the training contents. To do so, ten items on an ad hoc scale were used. The items were rated on a four-point Likert scale ranging from 1 (strongly disagree) to 4 (strongly agree). An example item is, "We used paralanguage signs (e.g., onomatopoeia, capital letters) to qualify our written messages". Reliability analyses show adequate values in the two experimental sessions: pre-training Cronbach's $\alpha$ was 0.81; posttraining Cronbach's $\alpha$ was 0.87. Aggregation at the team level was also performed [110] because the $\operatorname{rwg}(\mathrm{j})$ and ICC $(1)$ showed a proper fit. Pre-training rwg(j) was $0.85(\mathrm{SD}=0.11)$, and post-training $\mathrm{rwg}(\mathrm{j})$ was $0.84(\mathrm{SD}=0.12)$. Regarding the intraclass correlation, pretraining ICC(1) was 0.22 , and post-training ICC(1) was 0.37 . The results show that the values in the experimental $(\overline{\mathrm{x}}=2.45(\mathrm{SD}=0.55))$ and control $(\overline{\mathrm{x}}=2.59(\mathrm{SD}=0.56))$ conditions at pre-training did not differ $\left.\left(\mathrm{t}_{(50}\right)=-1.40 ; \mathrm{ns}\right)$. However, after the intervention, there were significant differences $\left(\mathrm{t}_{(50)}=2.33 ; p<0.01\right)$ between the experimental $(\overline{\mathrm{x}}=2.84(\mathrm{SD}=0.47))$ and control $(\bar{x}=2.55(S D=0.56))$ conditions in their use of affect management resources.

Regarding the identification with the bogus characteristics used to elicit subgroup perceptions, similar to prior research (e.g., [22]), we adapted two items from the relative in-group homogeneity scale [116]. Each team member was asked how much he or she identified with the bold profile and the thoughtful profile. The items were rated on a four-point Likert scale ranging from 1 (strongly disagree) to 6 (strongly agree). Since these can be considered single-item scales, reliability was not assessed. The results also support further analyses. Team members presented higher identification with their assigned profile than with the opposite profile. In the case of the thoughtful category, the perceived identification with this profile was higher than with the bold profile $(\overline{\mathrm{x}}=4.63(\mathrm{SD}=1.22)>$ $3.33(\mathrm{SD}=1.41))$, and this difference was significant $\left(\mathrm{t}_{(103)}=8.03 ; p<0.001\right)$. Similar results were found for the bold profile $(\bar{x}=4.39(\mathrm{SD}=1.22)>3.95(\mathrm{SD}=1.34))$, and this difference was also significant $\left(\mathrm{t}_{(103)}=2.39 ; p<0.05\right)$.

\subsection{Preliminary Results}

The data describing the characteristics of the sample (descriptive statistics: means and standard deviations) for the main variables used in the analyses are displayed in Table 1. Control variables and manipulation checks are not included. 
Table 1. Means and standard deviations for study variables.

\begin{tabular}{ccccc}
\hline Between-Subjects Condition & \multicolumn{2}{c}{ Control Groups } & \multicolumn{2}{c}{ Training Groups } \\
\hline Variables & Mean & SD & Mean & SD \\
\hline 1. Pre-intervention TWE & 4.85 & 0.42 & 4.72 & 0.54 \\
2. OEC team level & 3.6 & 0.24 & 3.5 & 0.22 \\
3. OEC Diversity & 0.52 & 0.23 & 0.52 & 0.23 \\
4. Post-intervention TWE & 4.8 & 0.61 & 5.1 & 0.53 \\
\hline
\end{tabular}

\subsection{Hypothesis Testing}

Hypothesis 1 proposed that affect management training would increase TWE levels in comparison with a control group. The results of the ANOVA reveal no global direct effect of the affect management training $(\mathrm{F}(1,50)=3.5 ; p=0.07 ; \eta p 2=0.063)$, and so comparing TWE at the pre- and post-training levels did not produce differences. However, as expected, the results showed an interaction effect $(\mathrm{F}(1,50)=5.4 ; p<0.05 ; \eta p 2=0.098)$ of the affect management training depending on the condition. Thus, there were differences in TWE before and after the training depending on whether the participant received the training (experimental condition) or not (control condition), with a medium effect size. As Figure 2 shows, in the pre-training session, mean values of TWE before the intervention were similar in teams in the control condition $(\mathrm{M}=4.85, \mathrm{SD}=0.09)$ and teams that received the training $(\mathrm{M}=4.81, \mathrm{SD}=0.11)$. However, after the intervention (post-training), teams that received the training significantly increased their TWE levels $(\mathrm{M}=5.1, \mathrm{SD}=0.11)$, whereas teams in the control condition slightly decreased their TWE $(\mathrm{M}=4.7, \mathrm{SD}=0.09)$.

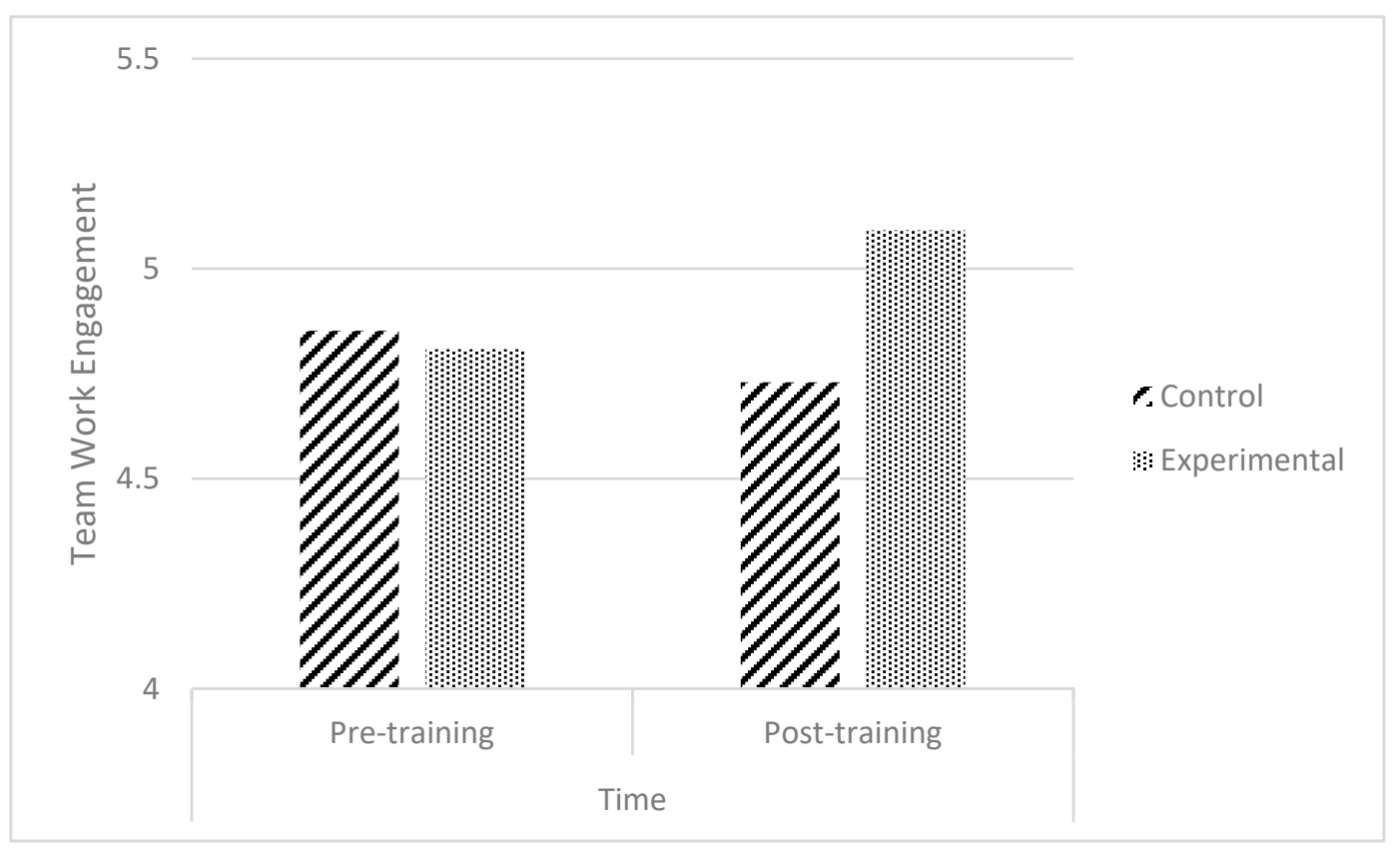

Figure 2. Comparison of the mean values of team work engagement (TWE).

Hypothesis 2 proposed that the best pattern of OEC to moderate the effects of the affect management training would consist of high team level OEC and low diversity.

The results of the OLS regression are shown in Table 2. Supporting Hypothesis 2, the regression coefficient for the three-way interaction term was statistically significant (Step $6, \beta=-6.16, \mathrm{t}=-2.25,95 \% \mathrm{CI}[-11,-0.64], p<0.05)$. Thus, as expected, there was a three-way interaction in which OEC team level and diversity interacted to influence the relationship between training and TWE. Moreover, this interaction added a significant per- 
centage of explained variance $(8 \%)$ to the independent explanatory power of the predictors, in addition to the individual moderating effects.

Table 2. Results of regression analyses for team work engagement.

\begin{tabular}{|c|c|c|c|c|c|c|}
\hline Predictors & Step 1 & Step 2 & Step 3 & Step 4 & Step 5 & Step 6 \\
\hline \multicolumn{7}{|l|}{ Main Effect } \\
\hline Engagement T1 & $0.327 \#$ & 0.380 * & $0.390 *$ & 0.401 * & 0.401 \# & $0.379 *$ \\
\hline Familiarity & 0.099 & 0.185 & 0.181 & 0.280 & 0.255 & 0.076 \\
\hline AFT & & $0.345^{*}$ & $0.348^{*}$ & 0.360 * & 0.353 & $0.280 \#$ \\
\hline OEC Level & & & 0.011 & 0.123 & 0.164 & 0.396 \\
\hline OEC Diversity & & & 0.201 & $0.940 \#$ & $0.976 \#$ & $1.15^{*}$ \\
\hline $\begin{array}{c}\text { Two-way interaction } \\
\text { AFT } \times \text { OEC level }\end{array}$ & & & & -0.07 & -0.05 & -0.53 \\
\hline AFT $\times$ OEC Diversity & & & & $-1.45 *$ & $-1.42 \#$ & $-1.83 *$ \\
\hline OEC Level $\times$ Diversity & & & & & 0.587 & $3.656 \#$ \\
\hline \multicolumn{7}{|l|}{ Three-way interaction } \\
\hline AFT $\times$ OEC Level $\times$ Diversity & & & & & & $-6.157 *$ \\
\hline $\mathrm{R}^{2}$ & 0.072 & 0.156 & 0.162 & 0.236 & 0.239 & 0.321 \\
\hline $\mathrm{F}$ & 1.88 & $2.96^{*}$ & 1.78 & $1.94 \#$ & 1.692 & $2.2 *$ \\
\hline$\Delta \mathrm{R}^{2}$ & 0.072 & $0.085^{*}$ & 0.006 & 0.074 & 0.003 & 0.082 * \\
\hline
\end{tabular}

Note. $\# p<0.1^{*} p<0.05 ;$; two-tailed. AFT = Affect Management Training; the regression coefficients shown are unstandardized.

As Figure 3 shows, we graphically represented the results for the conceptual model of the study. We show the coefficients of the direct (Hypothesis 1) and moderation effects of OEC in terms of team level and diversity (Hypothesis 2).

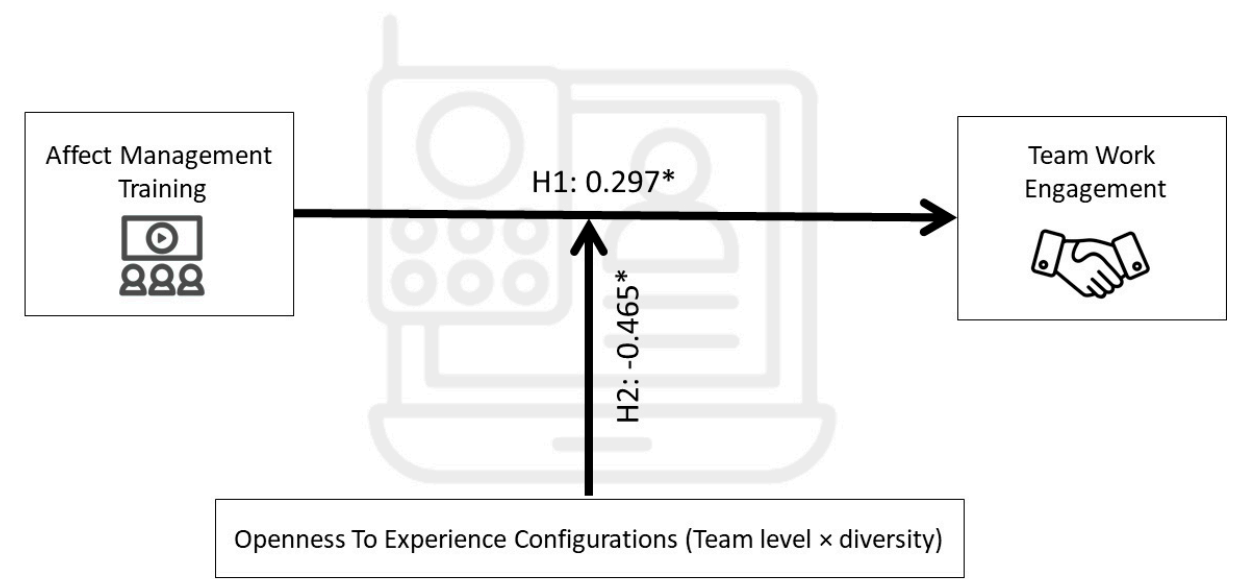

Figure 3. ${ }^{*} p<0.05$. Proposed conceptual model with hypotheses and standardized effects results.

Following Aiken and West [117], we interpreted this significant three-way interaction effect using the simple slope test, in order to find out whether the effect of the training on TWE was significant at specific high and low values (1 SD below and above the mean) of the moderating variables. As line 2 of the plot in Figure 4 shows, the effects of the training were positive and significant when there was high openness to experience at the team level and low diversity $(t=3.27, p<0.01)$, whereas the rest of the combinations were not significant. Specifically, the configurations of high level of openness to experience and diversity (1) $(t=-1.5, p=0.13)$ and low levels of openness with either high (3) $(t=1.1$, $p=0.267)$ or low diversity (4) $(t=1.67, p=0.103)$ did not produce significant results. Thus, we can conclude that the predicted pattern (high levels of openness to experience and low diversity) is the one that best helps to enhance the effects of the affect management training on TWE. 


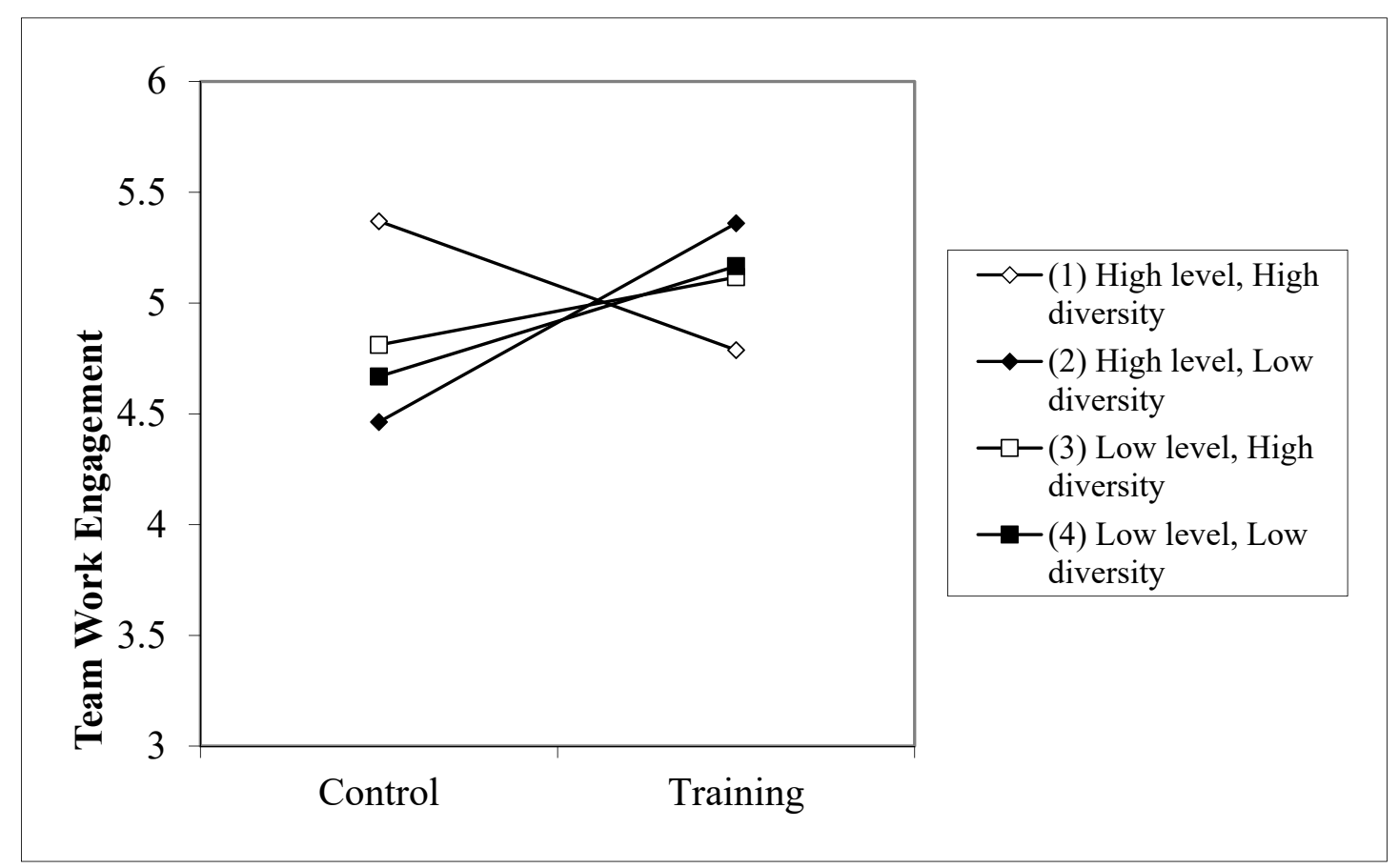

Figure 4. The moderated effect of openness to experience configurations (OEC) (team level and diversity) on the relationship between affect management training and TWE.

\section{Discussion}

Due to an increasing use of diverse workforces and the digitalization of work, virtual teamwork is inevitably ubiquitous. Thus, there is a need to study factors that promote its sustainability in terms of well-being and effectiveness. In this regard, the current study tested the efficacy of a short-term online affect management training to increase team work engagement (TWE) in students' virtual teams with subgroups. In addition, we examined different configurations of openness to experience (OEC) as moderators of the effects of the intervention. We tested whether there is a type of OEC, in terms of team level and diversity, that may increase the efficacy of the training.

Supporting Hypothesis 1, the results showed that teams that received affect management training increased their use of resources and strategies for sharing, interacting, and managing affective experiences in virtual teamwork, thus enhancing their TWE. We considered that virtual teams need to develop affective competencies because the process of computer-mediated communication differs from face-to-face interactions [47,74], where communication competences are informally developed. These competencies function as buffering resources in virtual environments, and so specific formal training is an appropriate intervention [34] to promote virtual teams' sustainability. In this way, technology provides opportunities for development and learning, which, if managed properly, can help correct the demands-resources incongruence that may produce disengagement $[16,34]$. Our intervention focused on the management of group affect in virtual environments. Prior literature highlights the importance of group affective experiences (e.g., $[45,118])$. Affect at the team level emerges because each member feels a similar level of certain affective experiences [43]. If the group can develop positive group affect, they will show more interest in the given task, attend to its requirements, dedicate time and effort, and feel more engaged [44]. However, in virtual environments, the synergy processes influencing affect may be diminished or even trigger negative affect due to the reduced richness of the environment, interactions, and information exchange $[10,47]$. The current study offers evidence that online training can provide resources and strategies to manage group affect. Thus, we were able to promote engagement at the group level by means of identifying, expressing, and regulating the expression of their own and other members' emotions through 
computer-mediated communication. We also highlighted the use of online strategies for fostering a positive affective climate, despite the potential threats and demands of the virtual environment.

Focusing on openness to experience, the results support Hypothesis 2. When applying our training, there is an optimum configuration consisting of a high level of openness to experience and low diversity in this trait among team members. This pattern increased the effects of the training, whereas other configurations did not show significant effects. As expected, the characteristics of open individuals (e.g., quick learners and capable in training environments, skilled in evaluating threats as possibilities, sensitive to new ways of working) facilitate features of the affect management training. This result supports previous research [119] where openness to experience moderated the relationship between the resources available in the group and engagement. Moreover, teams with high openness at the team level were expected to be more adaptable to the changing environments that often characterize virtual teamwork [67]. However, we go beyond previous research and test the combined effects of the two most common operationalizations: team level and diversity. Moreover, the study contributes to extending the theoretical framework of the trait activation theory [55] and the configuration perspective [54] to the context of virtual teams with subgroups, helping to understand the role played by openness to experience configurations.

These results have important implications for theoretical development and research. We contribute to the literature on virtual teams' well-being, sustainability, and group composition. First, our findings further support the importance of group affect in eudaimonic well-being [4,45], especially in virtual environments [47]. Thus, we respond to the call to study how well-being develops in virtual teams [4], with particular emphasis on the role of TWE as a proxy for eudaimonic well-being [3,4]. Considering the digitalization of work and life $[7,120,121]$, especially since the disruption caused by the COVID-19 health crisis [9], there is a need for sustainable teamwork. Moreover, sustainability in virtual environments is still an unfolding topic (e.g., [121]). Thus, to develop sustainable virtual teams, prior research highlighted the importance of focusing on engagement [16,41,49]. Our research adds value to prior results [49] by using synchronous virtual teams and a longitudinal (pre-post) design, which is a requirement in investigating the dynamic relationships between affect and motivation over time [44].

Second, these findings also yield support for short-term affect management interventions as a way of providing resources for working online, despite the potential detrimental effects of faultlines, thus providing support for the job demands-resources theory [29] in virtual teamwork studies. We built on this theory and previous literature $[18,33,41,74]$ by highlighting how the emotional and technological demands linked to working in a virtual environment and with subgroups may harm TWE, as well as the importance of providing affective resources to tackle this question. Our study suggests that affect management training will provide team members with a repertoire of strategies and resources that help them attenuate the negative effects of subgroups and virtuality and increase their TWE.

Third, this study adds a significant result to the broad personality composition literature. We help to create consensus in the personality composition literature by exploring which configuration(s) of openness to experience increase the effects of the training program. Thus, this study provides new unique insights into the way different patterns of one specific trait of personality may support the process of creating sustainable virtual teams. Whereas previous studies have considered different composition measures (e.g., team level, variability, best-member score), this study is unique because it combines them to form patterns that influence the effects of training on team well-being.

We specifically contribute to disentangling the black box of openness to experience configurations in virtual teams. We built on a contingent configuration approach [54] and drew on trait-activation theory [55] to propose a specific configuration of OEC (high team level, low diversity) that positively moderated the effects of the training. Our findings support these theories by suggesting that OEC plays an important role in shaping team 
members' perceptions and behaviors. Our results support the combined effects of both operationalizations, contributing to establishing a contingency framework and helping to advance current efforts to analyze personality composition in teams with faultlines and sustainable virtual environments. In this regard, our study advances the knowledge by investigating multiple configurations that influence the effects of affect management training on TWE. Understanding these moderating processes expands this area of research and leads to its further development, as well as pointing to practical implications for those interested in using short-term affective interventions to increase well-being.

Thus, we combined the team level and diversity of the trait in order to show a more complex picture of the phenomenon. To the best of our knowledge, this study is the first to test different OECs and their moderating role in fully dispersed virtual teams with subgroups with the goal of improving training effectiveness in increasing TWE. We showed that an optimal configuration of OEC exists, depending on the context and the outcome.

\subsection{Limitations and Future Research}

Despite the important contributions to theory and research, our study has some limitations. First, we conducted a randomized controlled trial with short-term ad hoc fully dispersed virtual teams composed mainly of young students from higher education institutions in Spain. This may limit the generalizability of our results because teams are usually partially dispersed, and virtuality is just one characteristic of their complex structure [122]. In addition, they are created from existing workers in an organization, and so there is a common background among members. Consequently, future research should analyze the effects of the affect management training on different types of virtual teams and extend the organizational context studied.

Moreover, due to the sample, generational differences may be influencing the results. It is possible that young students have developed early competencies for computer-mediated communication and feel more comfortable using it. Therefore, future research should aim to study established work teams with more tenured and older team members, or at least evaluate the impact of generational differences. In addition, regarding the design, and due to logistic constraints, we tested our hypotheses and conducted the intervention in a short period of time, and so we were only able to draw conclusions about the short-term effects of the training. Although our findings make a relevant contribution to theory and research due to the importance of training studies and the prevalence of virtual teams, future research should build on them to examine the long-term effects of affect management training on group well-being. Finally, we used a waitlist control design to test our hypotheses. This design is adequate [115], particularly if we consider the scarcity of virtual team intervention studies. This design is useful because it allows waitlisted participants to benefit from the intervention. However, to further support the role of training in building sustainable virtual teams, future studies should use active comparison conditions that can increase affect and well-being. For example, affect management training versus cognitive resources training, or interventions based on the use of computer-mediated tools, considering the job demands-resources theory [29], may help increase group well-being.

On a content level, we evaluated eudaimonic well-being as TWE. This is the most common form of eudaimonic well-being, and good quality, longitudinal research is necessary to address the relationship between group affect and team engagement [4]. However, further research needs to explore the role of other eudaimonic constructs at the team level, such as work purpose or collective flourishing, as well as combinations of hedonic and eudaimonic well-being constructs, so that happy sustainable teams can be achieved.

Another resource that can also be studied, as noted in prior research (e.g., $[6,8,15,32,123])$, is the role played by leaders in virtual teams. Leaders can help set clear team directions and build a supportive team climate [6].

Moreover, this work makes another contribution to the broader picture of personality composition studies in virtual teams and teams with subgroups. However, we only used one personality trait as a moderator. Although we heeded the call to use different group 
configurations when studying personality composition (e.g., [60]), we only did so for openness to experience. Despite this, other traits from the Big five factors model (e.g., extraversion $[53,61]$ ) are also of primary importance when interacting in virtual teams [67]. If we depart from the contingent perspective, the internal fit of multiple traits within groups is also possible and could be an interesting future avenue of research. Finally, recent research also highlights the role of other personality factors besides the Big Five (e.g., dark triad: Machiavellianism, narcissism, psychopathy) when studying effective teamwork [124]. Thus, future research can focus on multiple personality factors at the same time in order to observe their interactive effects.

\subsection{Practical Implications}

Our results also have some practical lessons for instructors, professors, HR professionals, and managers. First, eudaimonic well-being is a key factor in teams, educational organizations, and companies operating in turbulent environments [2,12]. However, many teams lack the proper competencies for adequate teamwork [12,125], in terms of the skills required for interaction, performance, and affective outcomes. Consequently, sustainable virtual teamwork is an unresolved matter, especially considering the recent disruptive digitalization, particularly in higher education contexts. In this regard, this study supports the use of short-term online training focused on team members' soft skills (i.e., affect management) to improve their engagement in their work or academic units. Thus, if team members can identify and regulate the affective experiences within the team, they will feel more focused and have more vigor and dedication. Particularly in academic environments, affect management could help to improve students' involvement in their work and, therefore, their academic performance.

Second, the proposed intervention can also help to overcome biases if diversity becomes problematic, especially considering the diminished information environment $[10,47]$ where virtual teams interact. Teamwork currently requires working with culturally diverse colleagues by means of virtual tools, and so it is necessary to prepare students for this reality [12]. Thus, by extending the evidence about effective ways to overcome the negative impact of faultlines [18,22], our findings provide team managers and professors with a tool for dealing with inter-group negative dynamics. Prior literature pointed out the need to study intervening variables that help identify the effects of affect and subgroups on team results [41], as well as mechanisms that attenuate their negative effects [23]. Through the proper management of affective experiences (affective computer-mediated communication techniques, resources, and strategies), virtual teams can reduce subgroups' negative effects, increasing their eudaimonic well-being.

Third, the way technology is designed and implemented is a key to whether it will be perceived as a resource or a job demand [34]. Thus, training can help manage the potential job demands stemming from structural conditions. As virtual teams continue to grow $[7,25]$ and the health pandemic forces the rapid generalization of virtual teamwork [26], many workers or students may lack the proper skills to cope with technologyrelated changes [12,34]. Thus, in this context, affect regulation and interventions (e.g., training) become critical $[27,34]$ in creating sustainable virtual teams. In this regard, this study provides support for the usefulness of online training and interaction tools (e.g., ZOOM, Blackboard Collaborate, use of webinars) in increasing team resources to improve group well-being in the short term in virtual teams of students.

Finally, our results for openness to experience provide a stimulus to reflect on the relevance of building teams by considering the personality traits of the members, as well as the way personality is aggregated to form configurations. Thus, when an organization or instructor creates a virtual team project, training helps promote well-being. However, it is important to look for members with high levels of openness to experience, and the selected members must be homogenous in terms of this trait in order to optimize the effects of the training. This is relevant for selection and team formation purposes because our findings 
suggest that different configurations of this trait can enhance the role of contextual tools such as organizational interventions.

Aside from our stated goals, these practical implications suggest some lessons for higher education contexts that are summarized in Table 3.

Table 3. Practical implications for educational contexts.

\section{Practical Implications of a Short Online Affect Management Training}

\section{For students:}

$\checkmark$... increases soft skills in virtual environments (identify and express emotions, use affect regulation strategies, management of non-verbal cues in online communication).

$\checkmark$...facilitates proper management of affective experiences (affective computer-mediated communication techniques, resources, and strategies), which may reduce diversity negative effects and increase their well-being.

For instructors:

$\checkmark$...provides a tool for dealing with inter-group negative dynamics and team resources to improve group well-being (engagement) in short-term virtual teams.

$\checkmark$... its effectiveness can be enhanced if teams are composed by "open" students (i.e., those with intellectual curiosity, tolerance to ambiguity, a preference for novelty and creativity).

\section{Conclusions}

As the literature continues to demonstrate the importance of promoting well-being in teams, little attention has been paid to applying and testing effective interventions that help to overcome the challenges of the virtual environment where organizational teams must interact. Based on this research, online training is an effective means to improve well-being. Thus, organizations aiming to create sustainable virtual teams should consider offering affect management training to their members. Our results also suggest that it is necessary to pay attention to openness to experience configurations, aiming for a pattern with a high team level and low diversity in this trait when applying affect management training programs. We encourage further studies along these lines to better understand how personality composition influences virtual teams. A research effort must be made to find new ways to improve eudaimonic well-being and create sustainable virtual teams.

Author Contributions: Conceptualization, B.G.-A., V.O., A.Z. and N.G.; methodology, B.G.-A., N.G. and V.P; software, B.G.-A. and V.P.; validation, N.G., A.Z. and V.O.; formal analysis, B.G.-A. and V.P.; investigation, B.G.-A., V.O., A.Z., N.G. and V.P.; resources, A.Z., N.G. and V.O.; data curation, V.P., N.G. and B.G.-A.; writing-original draft preparation, B.G, V.O and A.Z.; writing-review and editing, V.O., A.Z., V.P., N.G. and. B.G.-A.; Supervision, V.O and A.Z.; project administration, A.Z. and V.O.; funding acquisition, V.O., N.G., A.Z. and V.P. All authors have read and agreed to the published version of the manuscript.

Funding: This research was funded by Ministry of Science, Innovation and Universities, grant number PSI2016-79351-P. The APC was funded by PSI2016-79351-P. The first author had a research grant "FPU2016-01835".

Institutional Review Board Statement: The study was conducted according to the guidelines of the Declaration of Helsinki, and approved by the Institutional Review Board (Ethics Committee) of the University of Valencia, Spain (protocol code H1529924379218, date of approval: 5th of July-2018).

Informed Consent Statement: Individual informed consent was obtained from all subjects involved in the study.

Data Availability Statement: The data presented in this study are available on request from the corresponding author.

Acknowledgments: We thank the academic editor and the two anonymous reviewers for their constructive and insightful feedback, which greatly improved the quality of this article. 
Conflicts of Interest: The authors declare no conflict of interest. The funders had no role in the design of the study; in the collection, analyses, or interpretation of data; in the writing of the manuscript, or in the decision to publish the results.

\section{References}

1. Bayona, J.A.; Caballer, A.; Peiró, J.M. The relationship between knowledge characteristics' fit and job satisfaction and job performance: The mediating role of work engagement. Sustainability 2020, 12, 2336. [CrossRef]

2. Villajos, E.; Tordera, N.; Peiró, J.M. Human resource practices, eudaimonic well-being, and creative performance: The mediating role of idiosyncratic deals for sustainable human resource management. Sustainability 2019, 11, 6933. [CrossRef]

3. Peiró, J.; Montesa, D.; Soriano, A.; Kozusznik, M.W.; Villajos, E.; Magdaleno, J.; Djourova, N.P.; Ayala, Y. Revisiting the Happy-Productive Worker Thesis from a Eudaimonic Perspective: A Systematic Review. Sustainability 2021, 13, 3174. [CrossRef]

4. García-Buades, M.E.; Peiró, J.M.; Montañez-Juan, M.I.; Kozusznik, M.W.; Ortiz-Bonnín, S. Happy-productive teams and work units: A systematic review of the 'happy-productive worker thesis'. Int. J. Environ. Res. Public Health 2020, 17, 69. [CrossRef]

5. Raghuram, S.; Hill, N.S.; Gibbs, J.L.; Maruping, L.M. Virtual work: Bridging research clusters. Acad. Manag. Ann. 2019, 13, 308-341. [CrossRef]

6. Wilson, J.M.; Fletcher, T.D.; Pescosolido, T.; Major, D.A. Extraversion and Leadership Emergence: Differences in Virtual and Face-to-Face Teams. Small Group Res. 2021. [CrossRef]

7. Davidavičienè, V.; Al Majzoub, K.; Meidute-Kavaliauskiene, I. Factors Affecting Knowledge Sharing in Virtual Teams. Sustainability 2020, 12, 6917. [CrossRef]

8. Torre, T.; Sarti, D. The "Way" Toward E-leadership: Some Evidence From the Field. Front. Psychol. 2020, 11, 1-14. [CrossRef] [PubMed]

9. Parks, C.D. Introduction Group dynamics when battling a pandemic. Group Dyn. 2020, 24, 115-121. [CrossRef]

10. Hertel, G.; Geister, S.; Konradt, U. Managing virtual teams: A review of current empirical research. Hum. Resour. Manag. Rev. 2005, 15, 69-95. [CrossRef]

11. Jarvenpaa, S.L.; Leidner, D.E. Communication and trust in global virtual teams. J. Comput. Commun. 1998, 10, 791-815. [CrossRef]

12. Vidovic, M.; Hammond, M.; Lenhardt, J.; Palanski, M.; Olabisi, J. Teaching Virtual and Cross-Cultural Collaborations: Exploring Experiences of Croatia- and U.S.-Based Undergraduate Students. J. Manag. Educ. 2020. [CrossRef]

13. Han, S.J.; Beyerlein, M. Framing the Effects of Multinational Cultural Diversity on Virtual Team Processes. Small Group Res. 2016, 47, 351-383. [CrossRef]

14. van Knippenberg, D.; Mell, J.N. Past, present, and potential future of team diversity research: From compositional diversity to emergent diversity. Organ. Behav. Hum. Decis. Process. 2016, 136, 135-145. [CrossRef]

15. Stahl, G.K.; Maznevski, M.L.; Voigt, A.; Jonsen, K. Unraveling the effects of cultural diversity in teams: A meta-analysis of research on multicultural work groups. J. Int. Bus. Stud. 2010, 41, 690-709. [CrossRef]

16. Shaik, F.F.; Makhecha, U.P. Drivers of Employee Engagement in Global Virtual Teams. Australas. J. Inf. Syst. 2019, $23,1-45$. [CrossRef]

17. Boyraz, M. Faultlines as the "Earth's Crust": The Role of Team Identification, Communication Climate, and Subjective Perceptions of Subgroups for Global Team Satisfaction and Innovation. Manag. Commun. Q. 2019, 33, 581-615. [CrossRef]

18. Chiu, Y.T.; Staples, D.S. Reducing Faultlines in Geographically Dispersed Teams: Self-Disclosure and Task Elaboration. Small Group Res. 2013, 44, 498-531. [CrossRef]

19. Lau, D.C.; Murnighan, J.K. Demographic Diversity and Faultlines: The Compositional Dynamics of Organizational Groups. Acad. Manag. Rev. 1998, 23, 325. [CrossRef]

20. Thatcher, S.M.B.; Patel, P.C. Group Faultlines: A Review, Integration, and Guide to Future Research. J. Manag. 2012, 38, 969-1009. [CrossRef]

21. Johnson, S.K.; Bettenhausen, K.; Gibbons, E. Realities of working in virtual teams: Affective and attitudinal outcomes of using computer-mediated communication. Small Group Res. 2009, 40, 623-649. [CrossRef]

22. Rico, R.; Sánchez-Manzanares, M.; Antino, M.; Lau, D. Bridging team faultlines by combining task role assignment and goal structure strategies. J. Appl. Psychol. 2012, 97, 407-420. [CrossRef] [PubMed]

23. Valls, V.; Tomás, I.; González-Romá, V.; Rico, R. The influence of age-based faultlines on team performance: Examining mediational paths. Eur. Manag. J. 2020. [CrossRef]

24. Meyer, B.; Glenz, A.; Antino, M.; Rico, R.; González-Romá, V. Faultlines and Subgroups: A Meta-Review and Measurement Guide. Small Group Res. 2014, 45, 633-670. [CrossRef]

25. Coronas, T.T.; Oliva, M.A.; Luna, J.C.Y.; Palma, A.M.L. Virtual teams in higher education: A review of factors affecting creative performance. Adv. Intell. Syst. Comput. 2015, 369, 629-637. [CrossRef]

26. Feitosa, J.; Salas, E. Today's virtual teams: Adapting lessons learned to the pandemic context. Organ. Dyn. 2020, 100777. [CrossRef] [PubMed]

27. Restubog, S.L.D.; Ocampo, A.C.G.; Wang, L. Taking control amidst the chaos: Emotion regulation during the COVID-19 pandemic. J. Vocat. Behav. 2020, 119, 1-6. [CrossRef]

28. Nurmi, N. Coping with coping strategies: How distributed teams and their members deal with the stress of distance, time zones and culture. Stress Health 2011, 27, 123-143. [CrossRef] 
29. Demerouti, E.; Nachreiner, F.; Bakker, A.B.; Schaufeli, W.B. The job demands-resources model of burnout. J. Appl. Psychol. 2001, 86, 499-512. [CrossRef]

30. Sánchez-Cardona, I.; Rodriguez-Montalbán, R.; Acevedo-Soto, E.; Lugo, K.N.; Torres-Oquendo, F.; Toro-Alfonso, J. Self-Efficacy and Openness to Experience as Antecedent of Study Engagement: An Exploratory Analysis. Procedia Soc. Behav. Sci. 2012, 46, 2163-2167. [CrossRef]

31. Cao, C.; Shang, L.; Meng, Q. Applying the Job Demands-Resources Model to exploring predictors of innovative teaching among university teachers. Teach. Teach. Educ. 2020, 89, 103009. [CrossRef]

32. Pagán-castaño, E.; Sánchez-García, J.; Garrigos-simon, F.J.; Guijarro-García, M. The Influence of Management on Teacher Well-Being and the Development of Sustainable Schools. Sustainability 2021, 13, 2909. [CrossRef]

33. Derks, D.; Bakker, A.B. The impact of E-mail communication on organizational life. J. Psychosoc. Res. Cybersp. 2010, 4, 1-25.

34. Demerouti, E. Turn Digitalization and Automation to a Job Resource. Appl. Psychol. 2020, 1-6. [CrossRef]

35. Torrente, P.; Salanova, M.; Llorens, S.; Schaufeli, W.B. From "I" to "We": The Factorial Validity of a Team Work Engagement Scale. In Occupational Health Psychology: From Burnout to Well-Being; Neves, J., Gonçalves, S.P., Eds.; Edições Sílabo: Lisbon, Portugal, 2012; pp. 334-355.

36. Costa, P.L.; Passos, A.M.; Bakker, A.B. Team Work Engagement: Considering Team Dynamics for Engagement; ISCTE-IUL, Business Research Unit (BRU-IUL): Lisbon, Portugal, 2012; pp. 2-37.

37. Salanova, M.; Llorens, S.; Cifre, E.; Martínez, I.M.; Schaufeli, W.B. Perceived collective efficacy, subjective well-being and task performance among electronic work groups: An experimental study. Small Group Res. 2003, 34, 43-73. [CrossRef]

38. Costa, P.; Passos, A.M.; Bakker, A. Empirical validation of the team work engagement construct. J. Pers. Psychol. 2014, 13, 34-45. [CrossRef]

39. Cao, W.; Xu, L.; Liang, L.; Chaudhry, S.S. The impact of team task and job engagement on the transfer of tacit knowledge in e-business virtual teams. Inf. Technol. Manag. 2012, 13, 333-340. [CrossRef]

40. Gibbs, J.L.; Gibson, C.B.; Grushina, S.V.; Patrick, D.; Gibbs, J.L.; Gibson, C.B. Understanding orientations to participation: Overcoming status differences to foster engagement in global teams engagement in global teams ARTICLE HISTORY. Eur. J. Work Organ. Psychol. 2021. [CrossRef]

41. Gilson, L.L.; Maynard, M.T.; Jones Young, N.C.; Vartiainen, M.; Hakonen, M. Virtual Teams Research: 10 Years, 10 Themes, and 10 Opportunities. J. Manag. 2015, 41, 1313-1337. [CrossRef]

42. Marks, M.A.; Mathieu, J.E.; Zaccaro, S.J. A temporally based framework and taxonomy of team processes. Acad. Manag. Rev. 2001, 26, 356-376. [CrossRef]

43. Barsade, S.G.; Knight, A.P. Group Affect. Annu. Rev. Organ. Psychol. Organ. Behav. 2015, 2, 21-46. [CrossRef]

44. Salanova, M.; Llorens, S.; Schaufeli, W.B. "Yes, I Can, I Feel Good, and I Just Do It!” On Gain Cycles and Spirals of Efficacy Beliefs, Affect, and Engagement. Appl. Psychol. 2011, 60, 255-285. [CrossRef]

45. Gamero, N.; González-Romá, V. Affective Climate in Teams. In The Cambridge Handbook of Workplace Affect; Cambridge University Press: Cambridge, UK, 2020; pp. 244-256.

46. Derks, D.; Fischer, A.H.; Bos, A.E.R. The role of emotion in computer-mediated communication: A review. Comput. Human Behav. 2008, 24, 766-785. [CrossRef]

47. Cheshin, A.; Rafaeli, A.; Bos, N. Anger and happiness in virtual teams: Emotional influences of text and behavior on others' affect in the absence of non-verbal cues. Organ. Behav. Hum. Decis. Process. 2011, 116, 2-16. [CrossRef]

48. Salas, E. Team Training Essentials: A Research-Based Guide; Routledge: New York, NY, USA, 2015; ISBN 9781138814219.

49. Panteli, N.; Yalabik, Z.Y.; Rapti, A. Fostering work engagement in geographically-dispersed and asynchronous virtual teams. Inf. Technol. People 2019, 32, 2-17. [CrossRef]

50. LePine, J.A. Team adaptation and postchange performance: Effects of team composition in terms of members' cognitive ability and personality. J. Appl. Psychol. 2003, 88, 27-39. [CrossRef]

51. Colquitt, J.A.; Hollenbeck, J.R.; Ilgen, D.R.; Lepine, J.A.; Sheppard, L. Computer-assisted communication and team decisionmaking performance: The moderating effect of openness to experience. J. Appl. Psychol. 2002, 87, 402-410. [CrossRef] [PubMed]

52. Homan, A.C.; Hollenbeck, J.R.; Humphrey, S.E.; Van Knippenberg, D.; Ilgen, D.R.; Van Kleef, G.A. Facing differences with an open mind: Openness to experience, salience of intragroup differences, and performance of diverse work groups. Acad. Manag. J. 2008, 51, 1204-1222. [CrossRef]

53. Bell, S.T. Deep-level composition variables as predictors of team performance: A meta-analysis. J. Appl. Psychol. 2007, 92, 595-615. [CrossRef]

54. Moynihan, L.M.; Peterson, R.S. 7. A contingent configuration approach to understanding the role of personality in organizational groups. Res. Organ. Behav. 2001, 23, 327-378. [CrossRef]

55. Tett, R.P.; Burnett, D.D. A personality trait-based interactionist model of job performance. J. Appl. Psychol. 2003, 88, 500-517. [CrossRef] [PubMed]

56. Wang, Z.; Zhang, J.; Thomas, C.L.; Yu, J.; Spitzmueller, C. Explaining benefits of employee proactive personality: The role of engagement, team proactivity composition and perceived organizational support. J. Vocat. Behav. 2017, 101, 90-103. [CrossRef]

57. Halfhill, T.; Sundstrom, E.; Lahner, J.; Calderone, W.; Nielsen, T.M. Group personality composition and group effectiveness an integrative review of empirical research. Small Group Res. 2005, 36, 83-105. [CrossRef] 
58. Mohammed, S.; Angell, L.C. Personality heterogeneity in teams: Which Differences Make a Difference for Team Performance? Small Group Res. 2003, 34, 651-677. [CrossRef]

59. Neuman, G.A.; Wagner, S.H.; Christiansen, N.D. The Relationship between Work-Team Personality Composition and the Job Performance of Teams. Group Organ. Manag. 1999, 24, 28-45. [CrossRef]

60. Prewett, M.S.; Brown, M.I.; Goswami, A.; Christiansen, N.D. Effects of Team Personality Composition on Member Performance: A Multilevel Perspective. Group Organ. Manag. 2018, 43, 316-348. [CrossRef]

61. Balthazard, P.; Potter, R.E.; Warren, J. Expertise, Extraversion and Group Interaction Styles as Performance Indicators in Virtual Teams. Data Base Adv. Inf. Syst. 2004, 35, 41-64. [CrossRef]

62. Peeters, M.A.G.; Van Tuijl, H.F.J.M.; Rutte, C.G.; Reymen, I.M.M.J. Personality and team performance: A meta-analysis. Eur. J. Personal. 2006, 20, 377-396. [CrossRef]

63. Stipelman, B.A.; Rice, E.L.; Vogel, A.L.; Hall, K.L. The Role of Team Personality in Team Effectiveness and Performance. In Strategies for Team Science Success: Handbook of Evidence-Based Principles for Cross-Disciplinary Science and Practical Lessons Learned from Health Researchers; Springer: New York, NY, USA, 2019; pp. 189-196.

64. Anderson, M.H. The role of group personality composition in the emergence of task and relationship conflict within groups. J. Manag. Organ. 2009, 15, 82-96. [CrossRef]

65. van Vianen, A.E.M.; De Dreu, C.K.W. Personality in teams: Its relationship to social cohesion, task cohesion, and team performance. Eur. J. Work Organ. Psychol. 2001, 10, 97-120. [CrossRef]

66. Hollenbeck, J.R. The role of editing in knowledge development: Consensus shifting and consensus creation. In Opening the Black Box of Editorship; Palgrave Macmillan: London, UK, 2008; pp. 16-26. [CrossRef]

67. Hoch, J.E.; Dulebohn, J.H. Team personality composition, emergent leadership and shared leadership in virtual teams: A theoretical framework. Hum. Resour. Manag. Rev. 2017, 27, 678-693. [CrossRef]

68. Sonnentag, S. Dynamics of Well-Being. Annu. Rev. Organ. Psychol. Organ. Behav. 2015, 2, 261-293. [CrossRef]

69. Fisher, C.D. Happiness at Work. Int. J. Manag. Rev. 2010, 12, 384-412. [CrossRef]

70. Ryan, R.M.; Deci, E.L. On happiness and human potentials: A review of research on hedonic and eudaimonic well-being. Annu. Rev. Psychol. 2001, 52, 141-166. [CrossRef]

71. Bakker, A.B.; Demerouti, E. Job Demands-Resources Theory: Taking Stock and Looking Forward Job Demands-Resources Theory: Taking Stock and Looking Forward. J. Occup. Health Psychol. 2016, 22, 273-285. [CrossRef]

72. Schulze, J.; Schultze, M.; West, S.G.; Krumm, S. The Knowledge, Skills, Abilities, and Other Characteristics Required for Face-to-Face Versus Computer-Mediated Communication: Similar or Distinct Constructs? J. Bus. Psychol. 2017, 32, 283-300. [CrossRef]

73. Dulebohn, J.H.; Hoch, J.E. Virtual teams in organizations. Hum. Resour. Manag. Rev. 2017, 27, 569-574. [CrossRef]

74. Monzani, L.; Ripoll, P.; Peiró, J.M.; Van Dick, R. Loafing in the digital age: The role of computer mediated communication in the relation between perceived loafing and group affective outcomes. Comput. Hum. Behav. 2014, 33, 279-285. [CrossRef]

75. Kelly, J.R.; Barsade, S.G. Mood and emotions in small groups and work teams. Organ. Behav. Hum. Decis. Process. 2001, 86, 99-130. [CrossRef]

76. Ekman, P.; Friesen, W.V.; Scherer, K.R. Body movement and voice pitch in deceptive interaction. Semiotica 1976, 16, 23-28. [CrossRef]

77. Schulze, J.; Krumm, S. The "virtual team player": A review and initial model of knowledge, skills, abilities, and other characteristics for virtual collaboration. Organ. Psychol. Rev. 2017, 7, 66-95. [CrossRef]

78. Daft, R.L.; Lengel, R.H. Organizational Information Requirements, Media Richness and Structural Design. Manag. Sci. 1986. [CrossRef]

79. Byron, K. Carrying too heavy a load? The communication and miscommunication of emotion by email. Acad. Manag. Rev. 2008, 33, 309-327. [CrossRef]

80. Ashkanasy, N.M.; Dorris, A.D. Emotions in the Workplace. Annu. Rev. Organ. Psychol. Organ. Behav. 2017, 4, 67-90. [CrossRef]

81. Luse, A.; McElroy, J.C.; Townsend, A.M.; Demarie, S. Personality and cognitive style as predictors of preference for working in virtual teams. Comput. Hum. Behav. 2013, 29, 1825-1832. [CrossRef]

82. Molleman, E. Diversity in demographic characteristics, abilities and personality traits: Do faultlines affect team functioning? Group Decis. Negot. 2005, 14, 173-193. [CrossRef]

83. Barry, B.; Stewart, G.L. Composition, process, and performance in self-managed groups: The role of personality. J. Appl. Psychol. 1997, 82, 62-78. [CrossRef] [PubMed]

84. McCrae, R.R.; Costa, P.T. Validation of the Five-Factor Model of Personality Across Instruments and Observers. J. Pers. Soc. Psychol. 1987, 52, 81-90. [CrossRef] [PubMed]

85. Chiu, C.Y.C.; Owens, B.P.; Tesluk, P.E. Initiating and utilizing shared leadership in teams: The role of leader humility, team proactive personality, and team performance capability. J. Appl. Psychol. 2016, 101, 1705-1720. [CrossRef]

86. Peeters, M.A.G.; Rutte, C.G.; Van Tuijl, H.F.J.M.; Reymen, I.M.M.J. The big five personality traits and individual satisfaction with the team. Small Group Res. 2006, 37, 187-211. [CrossRef]

87. Schilpzand, M.C.; Herold, D.M.; Shalley, C.E. Members' openness to experience and teams' creative performance. Small Group Res. 2011, 42, 55-76. [CrossRef] 
88. Kramer, A.; Bhave, D.P.; Johnson, T.D. Personality and group performance: The importance of personality composition and work tasks. Pers. Individ. Differ. 2014, 58, 132-137. [CrossRef]

89. Kozlowski, S.W.J.; Klein, K.J. A multilevel approach to theory and research in organizations: Contextual, temporal, and emergent processes. In Multilevel Theory, Research, and Methods in Organizations: Foundations, Extensions, and New Directions; Klein, K.J., Kozlowski, S.W.J., Eds.; Jossey-Bass, Inc.: San Francisco, CA, USA, 2000; pp. 3-90.

90. Humphrey, S.E.; Hollenbeck, J.R.; Meyer, C.J.; Ilgen, D.R. Trait configurations in self-managed teams: A conceptual examination of the use of seeding for maximizing and minimizing trait variance in teams. J. Appl. Psychol. 2007, 92, 885-892. [CrossRef]

91. Costa, P.T.; McCrae, R.R. Normal Personality Assessment in Clinical Practice: The NEO Personality Inventory. Psychol. Assess. 1992, 4, 5-13. [CrossRef]

92. Korukonda, A.R. Differences that do matter: A dialectic analysis of individual characteristics and personality dimensions contributing to computer anxiety. Comput. Hum. Behav. 2007, 23, 1921-1942. [CrossRef]

93. Flynn, F.J. Having an open mind: The impact of openness to experience on interracial attitudes and impression formation. J. Pers. Soc. Psychol. 2005, 88, 816-826. [CrossRef]

94. De Vreede, T.; De Vreede, G.J.; Ashley, G.; Reiter-Palmon, R. Exploring the effects of personality on collaboration technology transition. Proc. Annu. Hawaii Int. Conf. Syst. Sci. 2012, 869-878. [CrossRef]

95. van den Hooff, B.; de Leeuw van Weenen, F. Committed to share: Commitment and CMC use as antecedents of knowledge sharing. Knowl. Process Manag. 2004. [CrossRef]

96. Chan, D. Functional relations among constructs in the same content domain at different levels of analysis: A typology of composition models. J. Appl. Psychol. 1998. [CrossRef]

97. Bowers, C.A.; Pharmer, J.A.; Salas, E. When member homogeneity is needed in work teams: A meta-analysis. Small Group Res. 2000, 31, 305-327. [CrossRef]

98. Roberson, Q.M.; Sturman, M.C.; Simons, T.L. Does the measure of dispersion matter in multilevel research?: A comparison of the relative performance of dispersion indexes. Organ. Res. Methods 2007, 10, 564-588. [CrossRef]

99. LePine, J.A.; Buckman, B.R.; Crawford, E.R.; Methot, J.R. A review of research on personality in teams: Accounting for pathways spanning levels of theory and analysis. Hum. Resour. Manag. Rev. 2011, 21, 311-330. [CrossRef]

100. Sanz-Martínez, L.; Er, E.; Martínez-Monés, A.; Dimitriadis, Y.; Bote-Lorenzo, M.L. Creating collaborative groups in a MOOC: A homogeneous engagement grouping approach. Behav. Inf. Technol. 2019, 38, 1107-1121. [CrossRef]

101. De Cooman, R.; Vantilborgh, T.; Bal, M.; Lub, X. Creating inclusive teams through perceptions of supplementary and complementary person-team fit: Examining the relationship between person-team fit and team effectiveness. Group Organ. Manag. 2015, 41, 310-342. [CrossRef]

102. Homan, A.C.; van Knippenberg, D.; Van Kleef, G.A.; De Dreu, C.K.W. Bridging Faultlines by Valuing Diversity: Diversity Beliefs, Information Elaboration, and Performance in Diverse Work Groups. J. Appl. Psychol. 2007, 92, 1189-1199. [CrossRef]

103. Meyer, B.; Shemla, M.; Schermuly, C.C. Social category salience moderates the effect of diversity faultlines on information elaboration. Small Group Res. 2011, 42, 257-282. [CrossRef]

104. McGrath, J.E. Groups: Interaction and Performance; Prentice-Hall: Englewood Cliffs, NJ, USA, 1984; Volume 14.

105. Martínez-Moreno, E.; Zornoza, A.; Orengo, V.; Thompson, L.F. The effects of team self-guided training on conflict management in virtual teams. Group Decis. Negot. 2015, 24, 905-923. [CrossRef]

106. Kalman, Y.M.; Scissors, L.E.; Gill, A.J.; Gergle, D. Online chronemics convey social information. Comput. Hum. Behav. 2013. [CrossRef]

107. Skovholt, K.; Grønning, A.; Kankaanranta, A. The Communicative Functions of Emoticons in Workplace E-Mails::-) Email literacy in the workplace View project Feedback and advice giving in teacher-student supervision View project. Artic. J. Comput. 2014. [CrossRef]

108. Benet-Martínez, V.; John, O.P. Los Cinco Grandes Across Cultures and Ethnic Groups: Multitrait Multimethod Analyses of the Big Five in Spanish and English. J. Pers. Soc. Psychol. 1998, 75, 729-750. [CrossRef]

109. de Bruin, G.P.; Henn, C.M. Dimensionality of the 9-item Utrecht work engagement scale (UWES-9). Psychol. Rep. 2013, 112, 788-799. [CrossRef] [PubMed]

110. Bliese, P.D. Within-group agreement, non-independence, and reliability: Implications for data aggregation and analysis. In Multilevel Theory, Research, and Methods in Organizations: Foundations, Extensions, and New Directions; Klein, K.J., Kozlowski, S.W.J., Eds.; Jossey-Bass, Inc.: San Francisco, CA, USA, 2000; pp. 349-381.

111. Maynard, M.T.; Mathieu, J.E.; Gilson LL, R.; Sanchez, D.; Dean, M.D. Do I Really Know You and Does It Matter? Unpacking the Relationship Between Familiarity and Information Elaboration in Global Virtual Teams. Group Organ. Manag. 2019, 44, 3-37. [CrossRef]

112. Janssen, J.; Erkens, G.; Kirschner, P.A.; Kanselaar, G. Influence of group member familiarity on online collaborative learning. Comput. Hum. Behav. 2009, 25, 161-170. [CrossRef]

113. Gruenfeld, D.H.; Mannix, E.A.; Williams, K.Y.; Neale, M.A. Group composition and decision making: How member familiarity and information distribution affect process and performance. Organ. Behav. Hum. Decis. Process. 1996, 67, 1-15. [CrossRef]

114. Harrison, D.A.; Mohammed, S.; Mcgrath, J.E.; Florey, A.T.; Vanderstoep, S.W. Time matters in team performance: Effects of member familiarity, entrainment, and task discontinuity on speed and quality. Pers. Psychol. 2003, 56, 633-669. [CrossRef] 
115. Locklear, L.R.; Taylor, S.G.; Ambrose, M.L. How a Gratitude Intervention Influences Workplace Mistreatment: A Multiple Mediation Model. J. Appl. Psychol. 2020. [CrossRef]

116. Bettencourt, B.A.; Molix, L.; Talley, A.; Eubanks, J.P. Numerical representation and cross-cut role assignments: Majority members' responses under cooperative interaction. J. Exp. Soc. Psychol. 2007, 43, 553-564. [CrossRef]

117. Aiken, L.S.; West, S.G. Multiple Regression: Testing and Interpreting Interactions.; Sage Publications: Thousand Oaks, CA, USA, 1991

118. Collins, A.L.; Jordan, P.J.; Lawrence, S.A.; Troth, A.C. Positive affective tone and team performance: The moderating role of collective emotional skills. Cogn. Emot. 2016, 30, 167-182. [CrossRef] [PubMed]

119. Bakker, A.B.; Sanz Vergel, A.I.; Kuntze, J. Student engagement and performance: A weekly diary study on the role of openness. Motiv. Emot. 2014, 39, 49-62. [CrossRef]

120. Cascio, W.F.; Montealegre, R. How Technology Is Changing Work and Organizations. Annu. Rev. Organ. Psychol. Organ. Behav. 2016, 3, 349-375. [CrossRef]

121. González-Anta, B.; Orengo, V.; Zornoza, A.; Peñarroja, V.; Martínez-Tur, V. Understanding the Sense of Community and Continuance Intention in Virtual Communities: The Role of Commitment and Type of Community. Soc. Sci. Comput. Rev. 2019, 1-18. [CrossRef]

122. Mathieu, J.E.; Gallagher, P.T.; Domingo, M.A.; Klock, E.A. Embracing Complexity: Reviewing the Past Decade of Team Effectiveness Research. Annu. Rev. Organ. Psychol. Organ. Behav. 2019, 6, 17-46. [CrossRef]

123. Hanna, A.A.; Smith, T.A.; Kirkman, B.L.; Griffin, R.W. The Emergence of Emergent Leadership: A Comprehensive Framework and Directions for Future Research. J. Manag. 2021, 47, 76-104. [CrossRef]

124. Nassif, A.G. Heterogeneity and centrality of "dark personality" within teams, shared leadership, and team performance: A conceptual moderated-mediation model. Hum. Resour. Manag. Rev. 2019, 29, 100675. [CrossRef]

125. Lacerenza, C.N.; Marlow, S.L.; Tannenbaum, S.I.; Salas, E. Team development interventions: Evidence-based approaches for improving teamwork. Am. Psychol. 2018, 73, 517-531. [CrossRef] 